\title{
Effects of neuromuscular block reversal with sugammadex versus neostigmine on postoperative respiratory outcomes after major abdominal surgery: a randomized-controlled trial \\ Effets du renversement du bloc neuromusculaire à l'aide de sugammadex vs de la néostigmine sur l'évolution respiratoire postopératoire après une chirurgie abdominale majeure: une étude randomisée contrôlée
}

\author{
Enrique Alday, MD, PhD (i) - Manolo Muñoz, MD • Antonio Planas, MD, PhD • \\ Esperanza Mata, MD • Carlos Alvarez, MD, PhD
}

Received: 11 September 2018/Revised: 11 April 2019/Accepted: 22 April 2019/Published online: 4 June 2019

(c) Canadian Anesthesiologists' Society 2019

\begin{abstract}
Purpose Postoperative pulmonary complications may be better reduced by reversal of neuromuscular block with sugammadex than by reversal with neostigmine because the incidence of residual block after sugammadex application is lower and diaphragm function is less impaired than after neostigmine administration. The aim of the study was to compare the effect of reversal of neuromuscular block with sugammadex or neostigmine on lung function after major abdominal surgery.

Methods One hundred and thirty adults scheduled for major abdominal surgery under combined general and epidural anesthesia were randomly allocated to receive 40 $\mu \mathrm{g}$ of neostigmine or $4 \mathrm{mg} \cdot \mathrm{kg}^{-1}$ of sugammadex to reverse neuromuscular block. Two blinded researchers performed spirometry and lung ultrasound before the surgery, as well as $1 \mathrm{hr}$ and $24 \mathrm{hr}$ postoperatively. Differences in mean changes from baseline were analyzed with repeated measures analysis of variance. Forced vital capacity (FVC) loss one hour after surgery was the main outcome. Secondary outcomes were differences in rate and size of atelectasis one hour and $24 \mathrm{hr}$ after surgery.

Results One hundred twenty-six patients were included in the main analysis. In the neostigmine group $(n=64)$, mean (95\% confidence interval [95\% CI]) reduction in FVC after
\end{abstract}

E. Alday, MD, PhD $(\bowtie) \cdot$ M. Muñoz, MD · A. Planas, MD, $\mathrm{PhD}$. E. Mata, MD - C. Alvarez, MD, PhD

Hospital Universitario La Princesa, C/Diego de León 62, 28006

Madrid, Spain

e-mail: kikealday@hotmail.com one hour was 0.5 (0.4 to 0.6) $L$. In the sugammadex group $(n=62)$, the mean $(95 \% \mathrm{CI})$ reduction in FVC during the first hour was 0.5 (95\% CI, 0.3 to 0.6) L. Thirty-nine percent of patients in the neostigmine group and $29 \%$ in the sugammadex group had visible atelectasis. Median [interquartile range (IQR)] atelectasis area was 9.7 [4.7$13.1] \mathrm{cm}^{2}$ and $6.8[3.6-12.5] \mathrm{cm}^{2}$, respectively.

Conclusion We found no differences in pulmonary function in patients reversed with sugammadex or neostigmine in a high-risk population.

Trial registration EudraCT 2014-005156-26; registered 27 May, 2015.

Résumé

Objectif Les complications pulmonaires postopératoires pourraient être mieux contrôlées en neutralisant le bloc neuromusculaire avec du sugammadex plutôt qu'avec de la néostigmine; en effet, l'incidence de bloc résiduel après l'administration de sugammadex est plus faible et la fonction $d u$ diaphragme moins affectée qu'après l'administration de néostigmine. L'objectif de cette étude était de comparer l'effet d'une neutralisation du bloc neuromusculaire réalisée à l'aide de sugammadex vs de la néostigmine sur la fonction pulmonaire après une chirurgie abdominale majeure.

Méthode Cent trente adultes devant subir une chirurgie abdominale majeure sous anesthésie générale et péridurale combinée ont été randomisés à recevoir $40 \mu \mathrm{g}$ de néostigmine ou $4 \mathrm{mg} \cdot \mathrm{kg}^{\mathrm{l}}$ de sugammadex afin de neutraliser le bloc neuromusculaire. Deux chercheurs en 
aveugle ont réalisé une spirométrie et une échographie pulmonaire avant la chirurgie, ainsi que 1 h et 24 h après l'opération. Les différences de changements moyens par rapport aux mesures de départ ont été analysées à l'aide de mesures répétées d'analyse de la variance. La perte de capacité vitale forcée (CVF) une heure après la chirurgie était notre critère d'évaluation principal. Les critères secondaires comprenaient les différences des taux et de taille de l'atélectasie une heure et 24 h après la chirurgie. Résultats Cent vingt-six patients ont été inclus dans l'analyse principale. Dans le groupe néostigmine ( $n=$ 64), la réduction moyenne (intervalle de confiance $95 \%$ [IC $95 \%$ ]) de CVF après une heure était de 0,5 (0,4 à 0,6) L. Dans le groupe sugammadex $(n=62)$, la réduction moyenne (IC $95 \%$ ) de CVF au cours de la première heure était de 0,5 (IC $95 \%, 0,3$ à 0,6) L. On a observé une atélectasie visible chez $39 \%$ des patients du groupe néostigmine et $29 \%$ des patients du groupe sugammadex. La surface médiane [écart interquartile (EIQ)] d'atélectasie était de 9,7 [4,7-13,1] $\mathrm{cm}^{2}$ et 6,8 [3,6-12,5] $\mathrm{cm}^{2}$, respectivement.

Conclusion Nous n'avons découvert aucune différence en ce qui touche à la fonction pulmonaire chez les patients neutralisés au sugammadex ou à la néostigmine dans une population à risque élevé.

Enregistrement de l'étude EudraCT 2014-005156-26; enregistrée le 27 mai 2015.

Respiratory muscle weakness and atelectasis secondary to abdominal surgery are major factors contributing to the development of postoperative pulmonary complications (PPCs). ${ }^{1}$ Residual neuromuscular block may increase the risk of PPCs. ${ }^{2-4}$ Reversal with sugammadex is associated with a lower incidence of residual paralysis at postanesthesia care unit (PACU) admission than reversal with neostigmine. ${ }^{5}$ Moreover, recent studies suggest that electromyographic activity of the diaphragm may be impaired after the use of neostigmine compared with sugammadex. ${ }^{6}$

Our hypothesis was that reversal of neuromuscular block with sugammadex would result in less postoperative pulmonary dysfunction than reversal with neostigmine. The primary objective of this study was to compare the change in forced vital capacity (FVC) one hour after reversal with neostigmine or sugammadex among patients undergoing major abdominal surgery. A secondary objective was to compare area of atelectasis size as assessed by planimetry in postoperative lung ultrasound images.

\section{Methods}

We carried out a randomized-controlled trial at Hospital Universitario La Princesa, a tertiary care university hospital in Madrid, Spain. The study was approved by the Human Research Ethics Committee (Chairperson Prof. Francisco Abad) on 19 November, 2014 and registered in the EU clinical trials register (EudraCT: 2014-005156-26). The trial was conducted from July 2015 to July 2016.

All patients scheduled for major abdominal surgery (liver resection, pancreatectomy, gastrectomy, or any type of colectomy) were included. Use of postoperative epidural analgesia was also an inclusion criterion. Exclusion criteria included: refusal to participate, admission to postoperative recovery unit under mechanical ventilation, hypersensitivity to any of the drugs, severe asthma or mild asthma under treatment, myocardial infarction or coronary occlusion three months prior to surgery, myasthenia gravis, emergency surgery, pulmonary fibrosis, or very severe chronic obstructive lung disease (GOLD IV). Informed consent was obtained by the residents on duty, the night before surgery.

\section{Study interventions}

Before entering the operating room, basal spirometry (KoKo ${ }^{\circledR}$ Legend, nSpire ${ }^{\mathrm{TM}}$ ) and lung ultrasound (LUS) (Sonosite M Turbo with a P21x Phased Array Probe, Sonosite, Bothell, WA, USA) were performed by an independent researcher. Spirometry was performed following international recommendations ${ }^{7}$ but with patients in a semi recumbent position $\left(40^{\circ}\right)$ as recommended for postoperative position. Forced vital capacity, forced expiratory volume in the first second $\left(\mathrm{FEV}_{1}\right)$, and forced expiratory flow $25-75 \%$ were measured. Changes in lung aeration were studied by LUS with the patients in the same position. Sagittal sections were performed at three areas in each lung: ventral, medial, and posterior, corresponding to three predefined locations (parasternal, medial axillary line, posterior axillary line). ${ }^{8}$ One to two complete respiratory cycles were recorded in each location for offline analysis. Collapsed areas were defined by sonography as the presence of a condensation "tissue-like" (hepatization) ultrasound pattern. For the offline analysis, a single frame corresponding to end expiration was selected from the video file. Brightness was adjusted setting the brightest level in the bony surface of ribs and the brightness level in the acoustic shadow behind ribs. After this adjustment, the scale in $\mathrm{cm}^{2}$ was set according to image resolution in pixels. Collapsed areas were then outlined and measured by planimetry. The sum of the six explored lung areas was considered the total collapsed area for the study. We used the software ImageJ 
(ImageJ, U. S. National Institutes of Health, Bethesda, MD, USA) for LUS image analysis. ${ }^{9}$

Combined epidural and general anesthesia were carried out by anesthesiologists as routine clinical practice. Neuromuscular block was performed with rocuronium and monitored by train-of-four (TOF) kinetomyography with Datex-Ohmeda MechanoSensor ${ }^{\mathrm{TM}}$. Anesthesiologists were free to maintain TOF level according to usual criteria. After the surgical resection was completed, patients were randomly assigned to receive either sugammadex 4 $\mathrm{mg} \cdot \mathrm{kg}^{-1}$ or neostigmine $40 \mu \mathrm{g} \cdot \mathrm{kg}^{-1}$ in combination with atropine $10 \mu \mathrm{g} \cdot \mathrm{kg}^{-1}$ using sealed opaque envelopes. An extra dose of reversal was permitted by protocol, when needed, at the discretion of the attending anesthesiologist. Unrestricted blocked randomization was previously carried out by an independent contract research organization with the program M.A.S (sampling and scheduled randomizations) Glaxo SmithKline version 2.1.

Reversal medications were unblinded to the anesthesiologist in the operating room but blinded for the patient and the researcher testing pulmonary function. Separated case report forms and databases were used for clinical and pulmonary data.

One hour after the patient was extubated, new spirometry and lung ultrasound explorations were performed in the postoperative recovery room with the same procedure and position used in the preoperative determinations. Postoperative clinical management was conducted according to clinical preferences. The day after surgery, prior to ward discharge from the postoperative recovery unit, or $24 \mathrm{hr}$ after extubation, additional pulmonary tests were performed.

Outcomes and data collection

\section{Clinical data}

Patient variables including age, height, weight, American Society of Anesthesiologists score, history of chronic obstructive pulmonary disease, congestive heart failure, basal peripheral capillary oxygen saturation $\left(\mathrm{SpO}_{2}\right)$, smoking, weight loss $>10 \%$, functional class, and respiratory infection in the last month were collected at baseline.

Surgical variables such as duration of surgery (skin-toskin), open vs laparoscopic approach, type of surgery, and anesthetic variables including tidal volume, positive endexpiratory pressure (PEEP), fraction of inspired oxygen $\left(\mathrm{F}_{\mathrm{I}} \mathrm{O}_{2}\right)$, need for alveolar recruitment (under anesthesiologist criteria), epidural analgesia, and amount of fluids administered were recorded during surgery.

Characteristics of the neuromuscular block including neuromuscular blocking drug, depth of block prior to reversal, reversal drug used, and last TOF percentage registered immediately before awakening were noted. Oxygenation was assessed by the $\mathrm{pO}_{2} / \mathrm{F}_{\mathrm{I}} \mathrm{O}_{2}$ ratio at the first hour after surgery and before discharge while $\mathrm{SpO}_{2}$ with ambient air was documented after spirometry. Hospital length of stay, Clavien-Dindo classification for postoperative complications, pneumonia, need for mechanical ventilation (invasive or non-invasive), and death were documented.

Variables confounding assessment of FVC such as body mass index, ARISCAT scale for postoperative risk of pulmonary complications, basal FVC and $\mathrm{FEV}_{1}$, residual neuromuscular block, and postoperative pain visual analogue scale (VAS) before and after spirometry were recorded.

\section{Outcomes}

Difference in reduction of FVC in the first hour between groups was the primary outcome. Other spirometry values were analyzed one hour and $24 \mathrm{hr}$ after surgery. Lung atelectasis size was measured by planimetry on ultrasound images as a secondary outcome. Differences in the incidence of hypoxemia (defined as $\mathrm{SpO}_{2} \leq 92 \%$ with $\mathrm{F}_{\mathrm{I}} \mathrm{O}_{2} 21 \%$ after spirometry, or partial pressure of oxygen $\left[\mathrm{pO}_{2}\right] / \mathrm{F}_{\mathrm{I}} \mathrm{O}_{2}<300$ with an $\mathrm{F}_{\mathrm{I}} \mathrm{O}_{2} 28-31 \%$ ) were also included in the secondary analysis. Incidence of nausea and vomiting in both groups was included as an exploratory analysis.

\section{Statistical analysis}

\section{Sample size}

In a previous unpublished study developed in our institution (2013) we found a mean loss of $18.1 \%$ and a standard deviation of $14.2 \%$ for the difference between basal FVC and FVC 30 min after surgery. We could not find data of previous studies in these settings reporting the clinical relevance of changes in FVC. For these reasons we estimated this relevance based on studies which analyzed changes in FVC and $\mathrm{FEV}_{1}$ after treatment with bronchodilators. $^{10,11}$ According to these studies, we considered as relevant a difference of $7 \%$ between groups. For a power of $80 \%$ with an $\alpha$ level (probability of a type I error) of 5\%, the sample size needed was 64 patients per group.

\section{Variable analysis}

Continuous variables were described by their measures of central tendency (mean or median) and dispersion (standard deviation or interquartile range). 


\section{CONSORT}

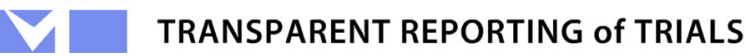

\section{CONSORT 2010 Flow Diagram}

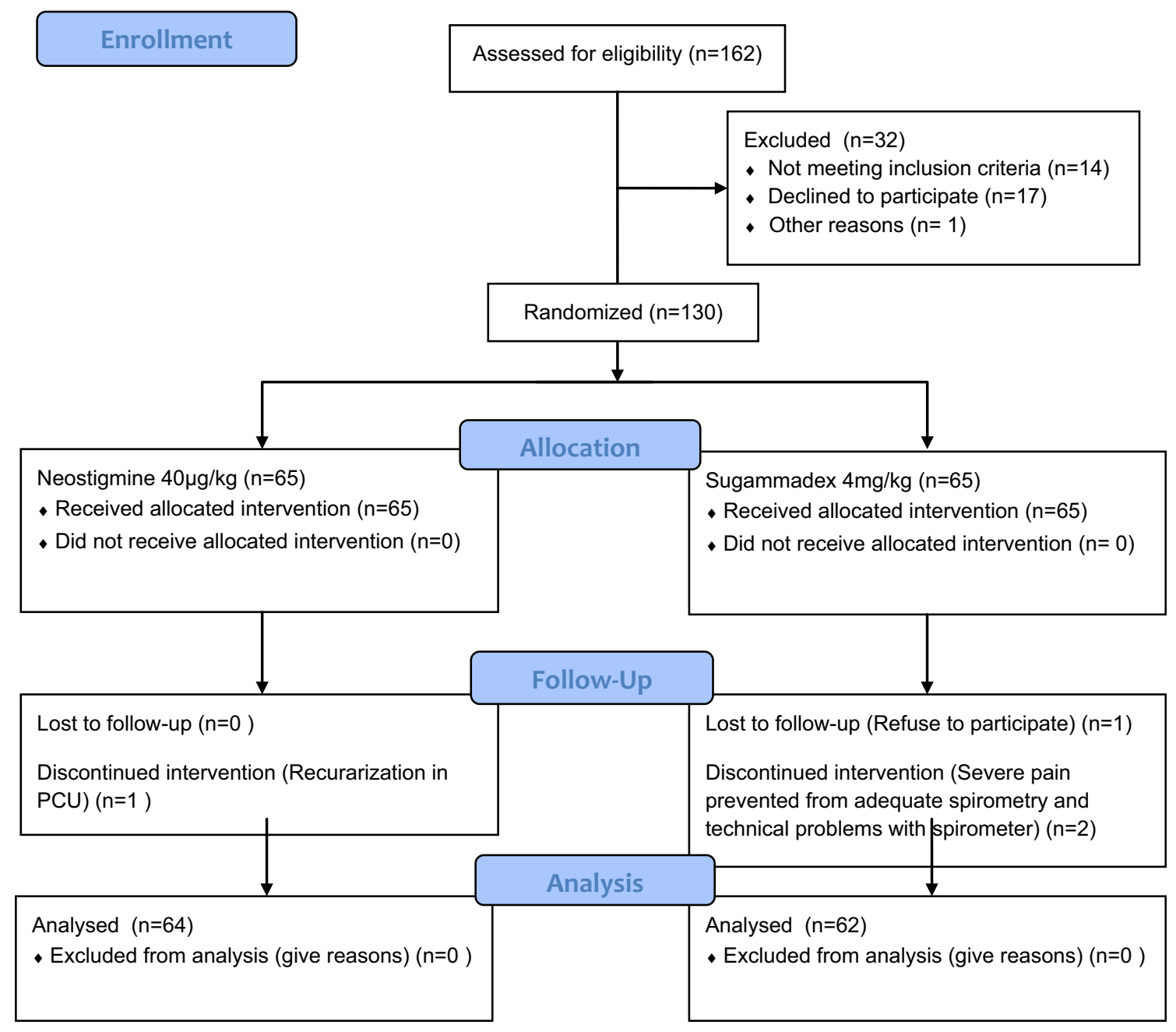

Fig. 1 Consort statement

Homoscedasticity was tested with Levene's test and normality with Shapiro-Wilk test. Differences in confounding factors between groups were analyzed with $\mathrm{t}$-test in case of quantitative variables and $\chi^{2}$ test for categorical variables. Corresponding non-parametric tests were used when needed. Differences in mean changes from baseline were analyzed with repeated measures analysis of variance (ANOVA) with treatment as a principal factor. Bonferroni post hoc test was used when $P \leq 0.05$ in ANOVA. If significant deviations from normality or the assumption of homoscedasticity were observed, a nonparametric test was used.

\section{Results}

One hundred and thirty patients were randomized $1: 1$ to receive either neostigmine $40 \mu \mathrm{g} \cdot \mathrm{kg}^{-1}+$ atropine 10 $\mu \mathrm{g} \cdot \mathrm{kg}^{-1}$ or sugammadex $4 \mathrm{mg} \cdot \mathrm{kg}^{-1}$. One patient was excluded from analysis in the neostigmine group because 
Table 1 Characteristics of participants

\begin{tabular}{|c|c|c|}
\hline & $\begin{array}{l}\text { Neostigmine } \\
(n=64)\end{array}$ & $\begin{array}{l}\text { Sugammadex } \\
(n=62)\end{array}$ \\
\hline Age $(y r)$, mean (SD) & $69.9(13.0)$ & $65.9(12.0)$ \\
\hline BMI $\left(\mathrm{kg} \cdot \mathrm{cm}^{-2}\right)$, mean $(\mathrm{SD})$ & $26.05(4.9)$ & $26.2(4.8)$ \\
\hline Gender, men $n(\%)$ & $32(50 \%)$ & $32(52 \%)$ \\
\hline \multicolumn{3}{|l|}{ ASA } \\
\hline $\mathrm{I}$ & $0(0)$ & $4(6)$ \\
\hline II & $38(59)$ & $35(56)$ \\
\hline III & $25(39)$ & $21(34)$ \\
\hline IV & $1(2)$ & $2(3)$ \\
\hline History of COPD, $n(\%)$ & $4(6)$ & $4(6)$ \\
\hline \multicolumn{3}{|l|}{ ARISCAT scale } \\
\hline Low & $24(37)$ & $25(40)$ \\
\hline Medium & $28(44)$ & $26(42)$ \\
\hline High & $12(19)$ & $11(18)$ \\
\hline \multicolumn{3}{|l|}{ Basal spirometry } \\
\hline FVC (L), mean (SD) & $3.0(1.0)$ & $3.0(1.0)$ \\
\hline$(\%$ predicted $)$, mean $(\mathrm{SD})$ & $80.7(19.9)$ & $75.1(18.3)$ \\
\hline $\mathrm{FEV}_{1}(\mathrm{~L})$, mean $(\mathrm{SD})$ & $2.2(0.8)$ & $2.4(0.9)$ \\
\hline (\% predicted), mean $(\mathrm{SD})$ & $80.9(20.8)$ & $79.8(19.7)$ \\
\hline $\mathrm{FEV}_{1} / \mathrm{FVC}(\%)$, mean $(\mathrm{SD})$ & $74(8)$ & $79(14)$ \\
\hline
\end{tabular}

ARISCAT = Canet's preoperative pulmonary risk index; ASA = American Society of Anesthesiologists physical status classification; COPD = chronic obstructive pulmonary disease; $\mathrm{FEV}_{1}=$ forced expiratory volume in first second; FVC = forced vital capacity; $\mathrm{SD}=$ standard deviation

of probable recurarization. This patient had one count in the TOF at reversal and four counts with a TOF ratio of 96\% immediately after extubation. Twenty minutes after arrival to PACU he suffered dyspnea, severe hypoxemia, and muscular weakness, which was treated with $200 \mathrm{mg}$ of sugammadex without monitoring muscular status. He was excluded from analysis because of protocol violation. In the sugammadex group one patient refused to participate before the one-hour spirometry, another patient could not have an adequate spirometry because of postoperative pain, and in one patient spirometry was not performed on time because of spirometer failure. Figure 1 shows the study flow chart.

Baseline and clinical characteristics

Demographic and clinical baseline characteristics were similar in both groups (Table 1). Surgical and anesthetic management are described in Table 2. At the moment of neuromuscular block reversal, the proportion of patients with deep neuromuscular block (TOF count equal to 0 ) was three of $64(5 \%)$ in the neostigmine group compared with 13 of $62(21 \%)$ in the sugammadex group $(P=0.007)$. Nevertheless, only 19 of $62(31 \%)$ of those reversed with sugammadex had TOF $<90 \%$ measured immediately after extubation compared with 45 of $64(71 \%)$ of those in the neostigmine group $(P<0.001)$.

Spirometry outcomes

Values of FVC at baseline, one, and $24 \mathrm{hr}$ following surgery, expressed in litres, are shown in Table 3. The decrease in FVC one hour after surgery, expressed as a percent of baseline, was $16 \%$ (95\% CI, 12 to 20 ) in the neostigmine group and $13 \%(95 \% \mathrm{CI}, 9$ to 18$)$ in the sugammadex group $(P=0.40)$. The day after surgery, decreases in FVC, expressed as a percent of baseline, were 24 (95\% CI, 20 to 29)\% and 24 (95\% CI, 20 to 29)\%, respectively $(P=0.94)$. Therefore, decreases in FVC one hour and one day after surgery were similar in both groups. $\mathrm{FEV}_{1}$ values in litres (not shown) decreased proportionally to FVC; relative differences were $15 \%$ one hour $(95 \% \mathrm{CI}$, 11 to 18 ) and $25 \%$ (95\% CI, 21 to 29$)$ one day after surgery. Again, there were no differences were between groups.

Atelectasis on lung ultrasound

Examples of ultrasound technique and measurements are shown in Figs 2-4. Three patients were excluded from the 
Table 2 Surgical and anesthetic management

\begin{tabular}{|c|c|c|}
\hline & Neostigmine $(n=64)$ & Sugammadex $(\underline{n}=62)$ \\
\hline \multicolumn{3}{|l|}{ Surgery procedure, $n(\%)$} \\
\hline Gastric/small bowel, $n(\%)$ & $7(11)$ & $6(10)$ \\
\hline Liver resection, $n(\%)$ & $7(11)$ & $8(13)$ \\
\hline Pancreatic resection, $n(\%)$ & $6(9)$ & $4(6)$ \\
\hline Colorectal, $n(\%)$ & $41(64)$ & $39(63)$ \\
\hline Others, $n(\%)$ & $3(5)$ & $5(8)$ \\
\hline \multicolumn{3}{|l|}{ Surgical approach } \\
\hline Laparoscopic, $n(\%)$ & $39(61)$ & $30(48)$ \\
\hline Open surgery, $n(\%)$ & $25(39)$ & $32(52)$ \\
\hline \multicolumn{3}{|l|}{ Anesthetic management } \\
\hline $\mathrm{Vt} \mathrm{mL} \cdot \mathrm{kg}^{-1}$, mean $(\mathrm{SD})$ & $8.1(1.1)$ & $8.1(1.2)$ \\
\hline PEEP, mean (SD) & $7.7(5.6)$ & $7.7(2.5)$ \\
\hline $\mathrm{F}_{1} \mathrm{O}_{2}(\mathrm{mmHg})$, mean $(\mathrm{SD})$ & $0.5(0.7)$ & $0.5(0.9)$ \\
\hline Alveolar recruitment, $n(\%)$ & $15(23.4)$ & $27(43.6)$ \\
\hline Rocuronium dose (mg), mean (SD) & $113(41)$ & $126(39)$ \\
\hline Reversal drug dose $\left(\mu \mathrm{g} \cdot \mathrm{kg}^{-1}\right.$ or $\left.\mathrm{mg} \cdot \mathrm{kg}^{-1}\right)$, mean (SD) & 39. (2.7) & $4.0(0.4)$ \\
\hline Intraoperative balance $\left(\mathrm{mL} \cdot \mathrm{kg}^{-1} \mathrm{hr}^{-1}\right)$, mean (SD) & $5.9(4.2)$ & $5.2(2.8)$ \\
\hline Surgery duration $(\mathrm{min})$, median $[\mathrm{IQR}]$ & $192.5[155-240]$ & $210[165-280]$ \\
\hline $\mathrm{TOF}=0$ before reversal, $n(\%)$ & $3(5) *$ & $13(21) *$ \\
\hline Residual NMB (TOF < 90\%), $n(\%)$ & $45(71) * *$ & $19(31) * *$ \\
\hline Residual NMB (TOF < 70\%), $n(\%)$ & $11(17)$ & $4(6)$ \\
\hline
\end{tabular}

$\mathrm{F}_{1} \mathrm{O}_{2}=$ fraction of inspired oxygen; Intraoperative balance $=($ crystalloids $(\mathrm{mL})+$ colloids $(\mathrm{mL})+$ hemoderivatives $(\mathrm{mL})-$ urine output $(\mathrm{mL})$ - bleeding $(\mathrm{mL})) /($ surgery duration $(\mathrm{hr})) \times($ weight $(\mathrm{kg})) ; \mathrm{IQR}=$ interquartile range; $\mathrm{NMB}=$ neuromuscular block defined immediately after extubating; $\mathrm{PEEP}=$ positive end expiratory pressure, $\mathrm{TOF}=$ train-of-four; $\mathrm{Vt}=$ tidal volume adjusted to ideal weight. $* P$ value $=0.007 ; * * P$ value $<0.001$

Table 3 Forced vital capacity at baseline, and one hour and $24 \mathrm{hr}$ following surgery

\begin{tabular}{|c|c|c|}
\hline & Neostigmine $n=64$ & Sugammadex $n=62$ \\
\hline Basal FVC & $3.0(0.1)$ & $3.0(0.1)$ \\
\hline $1^{\text {st }}$ hour FVC & $2.5(0.1)$ & $2.6(0.1)$ \\
\hline Difference $1^{\text {st }}$ hour $v s$ basal** & $\begin{array}{l}0.5(0.6)^{*} \\
(0.4 \text { to } 0.6)\end{array}$ & $\begin{array}{l}0.4(0.6)^{*} \\
(0.3 \text { to } 0.6)\end{array}$ \\
\hline $24 \mathrm{hr} F V C$ & $2.2(0.1)$ & $2.2(0.1)$ \\
\hline Difference $24 \mathrm{hr} v s$ basal ${ }^{* *}$ & $\begin{array}{l}0.8(0.6)^{*} \\
(0.6 \text { to } 0.9)\end{array}$ & $\begin{array}{l}0.8(0.6)^{*} \\
(0.6 \text { to } 0.9)\end{array}$ \\
\hline
\end{tabular}

Data expressed in liters. Mean (SD) $.95 \% \mathrm{CI}=95 \%$ confidence interval; $\mathrm{FVC}=$ forced vital capacity, $1 . \mathrm{SD}=$ standard deviation. $* P$ value $($ time factor) $\leq 0.001$. $* * P$ value (treatment factor) $>0.20$

lung ultrasound analysis after one hour in the neostigmine group because of basal abnormalities (consolidation or pleural effusion). Forty-two patients had visible new consolidations in the first hour (Table 4). Twenty-four of them $(39 \%)$ were in the neostigmine group and $18(30 \%)$ were in the sugammadex group. Median atelectasis size was $9.7 \mathrm{~cm}^{2}$ in those patients who received neostigmine and $6.7 \mathrm{~cm}^{2}$ when sugammadex was employed for neuromuscular block reversal (Table 4).

The number of patients with lung consolidations at the first day after surgery increased to $43(74 \%)$ in the neostigmine group and to $39(66 \%)$ in the sugammadex group. Median atelectasis size was $17.0 \mathrm{~cm}^{2}$ and $13.6 \mathrm{~cm}^{2}$, respectively. No statistically significant differences were found during the early postoperative period. 


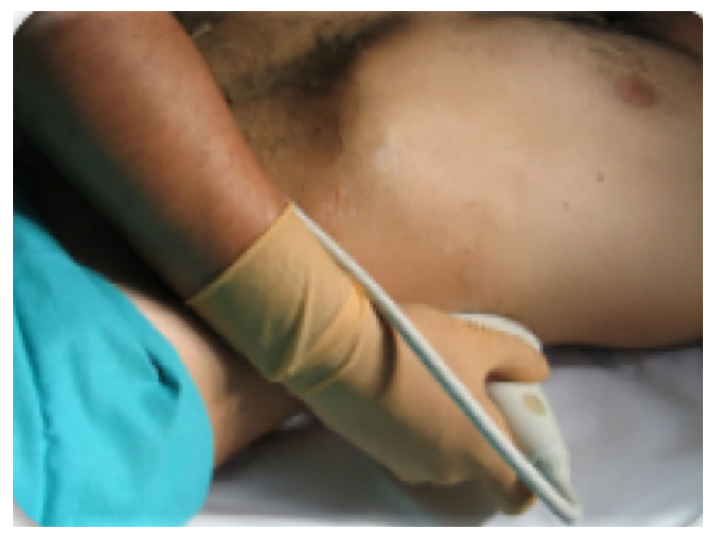

Fig. 2 Probe located in last intercostal space, posterior axillary line in a sagittal orientation

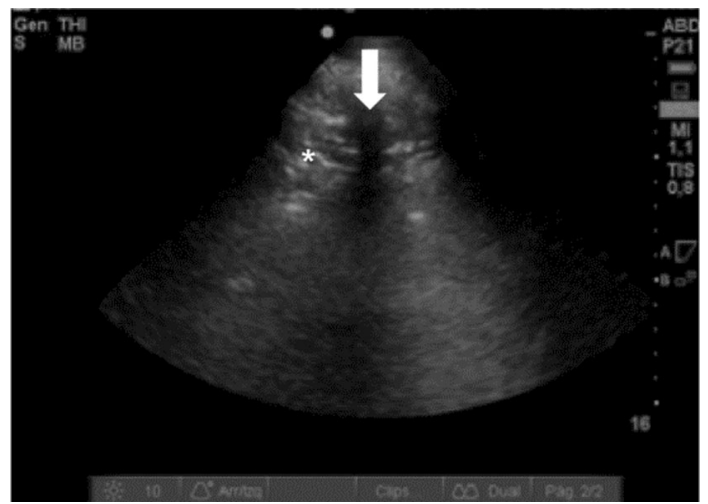

Fig. 3 Arrow = border of the rib with acoustic shadowing beneath it. Asterisk = lung consolidation

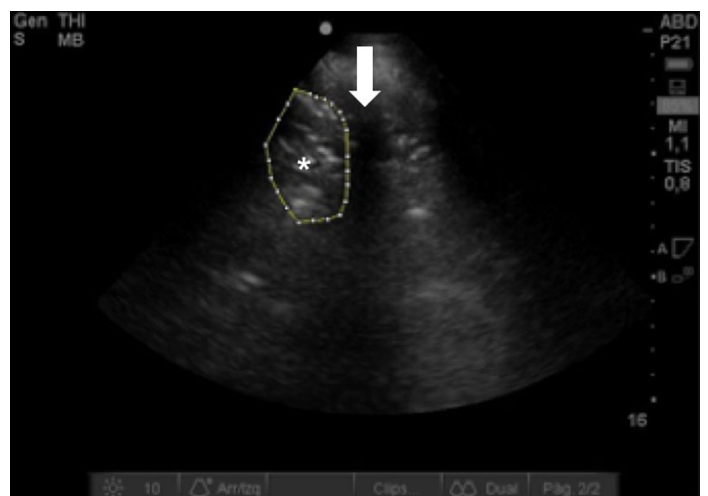

Fig. 4 Arrow $=$ border of the rib with acoustic shadowing beneath it. Asterisk = lung consolidation. Consolidation area is outline using manual tracing tools in ImageJ software. Area is calculated after adjusting scale with the same software

\section{Postoperative complications}

Incidence of postoperative hypoxemia $\left(\mathrm{SpO}_{2} \leq 92\right)$, measured without oxygen after a spontaneous recruitment maneuver (spirometry) or with oxygen when $\mathrm{pO}_{2} / \mathrm{F}_{1} \mathrm{O}_{2}$ rate was lower than 300 , was similar in both groups (Table 5). The day after surgery, one $(1 \%)$ patient in the neostigmine group and $10(16 \%)$ patients in the sugammadex group had a $\mathrm{SpO}_{2}$ with ambient air after spirometry of less than $92 \%$. There were no differences between groups in respiratory complications, other postoperative complications, need for mechanical ventilation, or death (Table 5).

\section{Discussion}

We found no differences in postoperative spirometry at one and $24 \mathrm{hr}$ after surgery in patients who received sugammadex or neostigmine to reverse neuromuscular block. FVC decreased by approximately 15\% compared with baseline one hour postoperatively in both study groups, an amount lower than expected for upper abdominal surgery. ${ }^{4,12,13}$ Previous data describing FVC loss after surgery are heterogeneous and were published many years ago. After upper abdominal surgery, a loss of at least $30 \%$ of FVC is expected. ${ }^{14}$ We believe that good postoperative analgesia and patient cooperation was responsible for the reported preservation of FVC. ${ }^{15}$

Atelectasis may occur in up to $90 \%$ of anesthetized patients ${ }^{16}$ and is suspected when oxygenation is impaired after surgery. The rate of postoperative atelectasis, especially one hour after general anesthesia is not well documented. In our population, incidence of atelectasis measured by LUS one hour after surgery was lower than expected. Intraoperative low tidal volume $(\mathrm{Vt})$ ventilation with PEEP may reduce the incidence of atelectasis and pulmonary complications. ${ }^{17-19}$ In our patients, the mean Vt was $8 \mathrm{~mL} \cdot \mathrm{kg}^{-1}$ ideal body weight with very low dispersion and PEEP above $4 \mathrm{cmH}_{2} \mathrm{O}$ was applied in every patient. Lung ultrasound is a novel and accurate technique for postoperative lung collapse diagnosis, ${ }^{20}$ but may be less sensitive than computed tomography.

Although there is not a unanimous definition for PPCs, clinically relevant pulmonary complications after elective major abdominal surgery are uncommon. ${ }^{1}$ Such was the case in our study with only four patients requiring mechanical ventilation and two developing pneumonia. Our study focused on process markers like changes in FVC and atelectasis that might be a starting point for clinically relevant pulmonary complications. Surprisingly, both FVC loss and incidence and size of atelectasis were higher the day after surgery. Protective mechanical ventilation may have influenced the benefit found in the first hour. Lack of early mobilization, positive fluid balance, or inconsistent chest physiotherapy may have increased atelectasis as time passed. ${ }^{21}$ It is unlikely to be related to the agent used for neuromuscular block reversal. 
Table 4 Atelectasis on lung ultrasound

\begin{tabular}{lll}
\hline & Neostigmine & Sugammadex \\
\hline $1^{\text {st }}$ hour atelectasis rate $(\%)^{*}$ & $24 / 61(39)$ & $18 / 61(30)$ \\
$24 \mathrm{hr}$ atelectasis rate $(\%)^{*}$ & $42 / 58(74)$ & $39 / 59(66)$ \\
$1^{\text {st }}$ hour atelectasis size $\left(\mathrm{cm}^{2}\right)$ Median $[\mathrm{IQR}]^{*}$ & 9.7 & 6.8 \\
& {$[4.7-13.0]$} & {$[3.6-12.5]$} \\
$24 \mathrm{hr}$ atelectasis size $\left(\mathrm{cm}^{2}\right)$ Median $[\mathrm{IQR}]^{*}$ & 16.98 & 13.54 \\
& {$[8.3-24.3]$} & {$[6.7-25.5]$} \\
\hline
\end{tabular}

IQR = interquartile range. Atelectasis size: data from patients with atelectasis

$* P$ value (treatment factor) $>0.25$

Table 5 Postoperative events

\begin{tabular}{|c|c|c|}
\hline & $\begin{array}{l}\text { Neostigmine } \\
(n=64)\end{array}$ & $\begin{array}{l}\text { Sugammadex } \\
(n=62)\end{array}$ \\
\hline \multicolumn{3}{|c|}{ PO hypoxemia $\left(\mathrm{SpO}_{2} \leq 92 \% ; \mathrm{F}_{1} \mathrm{O}_{2} 0.21\right)$} \\
\hline $1^{\text {st }}$ hour, $n(\%)$ & $14(21)$ & $17(27)$ \\
\hline $24 \mathrm{hr}, n(\%)$ & $1(1) *$ & $10(16) *$ \\
\hline \multicolumn{3}{|l|}{ PO hypoxemia $\left(\mathrm{pO}_{2} / \mathrm{F}_{1} \mathrm{O}_{2}<300\right)$} \\
\hline $1 \mathrm{hr}, n(\%)$ & $8(12)$ & $7(11)$ \\
\hline $24 \mathrm{hr}, n(\%)$ & $3(4)$ & $8(12)$ \\
\hline \multicolumn{3}{|l|}{ Assisted ventilation } \\
\hline Use of NIV, $n(\%)$ & $0(0)$ & $2(3)$ \\
\hline $\begin{array}{l}\text { Use of postoperative MV, } n \\
(\%)\end{array}$ & $2(3)$ & $2(3)$ \\
\hline Pneumonia, $n(\%)$ & $1(1)$ & $1(1)$ \\
\hline \multicolumn{3}{|l|}{ Postoperative analgesia } \\
\hline VAS $1^{\text {st }}$ hour median $[\mathrm{IQR}]$ & $0[0-3]$ & $0[0-3]$ \\
\hline VAS $24 \mathrm{hr}$ median [IQR] & $0[0-2]$ & $1[0-3]$ \\
\hline \multicolumn{3}{|l|}{ Surgical complications ${ }^{\mathrm{a}}$} \\
\hline Type I, $n(\%)$ & $8(12)$ & $8(13)$ \\
\hline Type II, $n(\%)$ & $12(19)$ & $8(13)$ \\
\hline Type IIIa, $n(\%)$ & $5(8)$ & $4(6)$ \\
\hline Type IIIb, $n(\%)$ & $0(0)$ & $2(3)$ \\
\hline Type Iva, $n(\%)$ & $1(2)$ & $5(8)$ \\
\hline Type IVb, $n(\%)$ & $4(6)$ & $3(5)$ \\
\hline Type V (death), $n(\%)$ & $1(2)$ & $1(2)$ \\
\hline $\begin{array}{l}\text { Length of stay (days), mean } \\
\text { (SD) }\end{array}$ & $11.4(8.4)$ & $12.9(10.6)$ \\
\hline
\end{tabular}

$\mathrm{a}=$ Clavien-Dindo classification; $\mathrm{F}_{1} \mathrm{O}_{2}=$ fraction of inspired oxygen; $\mathrm{IQR}=$ interquartile range; $\mathrm{MV}=$ mechanical ventilation; NIV = noninvasive ventilation; $\mathrm{PO}=$ postoperative; $\mathrm{pO}_{2}=$ partial pressure of oxygen; VAS = visual analogue scale. $* P=0.013$

Residual neuromuscular paralysis is a frequent complication of general anesthesia with an incidence of up to $30 \%{ }^{3,22}$ reported in the literature. Our study, despite the open use of quantitative neuromuscular monitoring, was no different. Despite protocolized monitoring of neuromuscular block, and the possibility of using rescue doses of neostigmine, none of the clinical researchers used more than $40 \mu \mathrm{g} \cdot \mathrm{kg}^{-1}$. More than two thirds of patients in the neostigmine group and nearly one third of those in the sugammadex group had a TOF ratio $\leq 90 \%$ immediately after extubation. Although we determined TOF ratio immediately after extubation instead of in the PACU, as commonly done, ${ }^{23}$ the proportion of patients with an inadequate reversal was high. Previous research showed an association between residual neuromuscular block and PPCs. ${ }^{3}$ Our study was not designed to evaluate this association.

A recently published multicentre prospective observational study including 22,803 patients did not show any advantage of sugammadex over neostigmine with respect to preventing pulmonary complications. ${ }^{24}$ Moreover, extubation with a TOF ratio $>90 \%$ was not associated with a lower risk of postoperative respiratory complications. Authors concluded that using neuromuscular agents during anesthesia is associated with an increased risk of postoperative pulmonary complications irrespective of dose. Diaphragm impairment after surgery, immobilization, and inflammatory response may have a more relevant influence in postoperative pulmonary outcomes than reversal agents.

There are limitations to our study. Use of recruitment maneuvers was not controlled and 27 (44\%) patients in the sugammadex group received this intervention during surgery compared with $15(23 \%)$ in the neostigmine group. The PROVHILO trial did not show differences in pulmonary outcomes when a recruitment maneuver followed by a PEEP of $12 \mathrm{cmH}_{2} \mathrm{O}$ was performed. ${ }^{25}$ The iPROVE trial also failed to prove better oxygenation three hours after surgery or a lower rate of atelectasis during the first day with an intraoperative open lung strategy with individual PEEP assessment. ${ }^{26}$ We believe this had little impact on our results. Secondly, anesthesiologists in the operation room were not blinded to the study drug and managed neuromuscular block under their own criteria. This could have biased results because of different rocuronium dose regimens. Total rocuronium dose was 
$10 \%$ higher in the sugammadex group but time of surgery was also slightly higher for these patients. The rate of TOF $=0$ before reversal was significantly higher in the sugammadex group. We did not record post tetanic count before reversal when $\mathrm{TOF}=0$. These patients might have been at risk of symptomatic residual neuromuscular block but with respect to our findings and the main point of our results, none of these factors influenced postoperative lung function one hour after surgery.

In conclusion, we found no differences in spirometry after reversal with sugammadex or neostigmine in a highrisk population with intraoperative lung-protective ventilation, neuromuscular block monitoring, and epidural analgesia. No difference in the incidence of atelectasis, area of atelectasis, or pulmonary complications was noted. The benefit of sugammadex might be related to the reduction of infrequent critical respiratory events during the immediate postoperative period due to severe residual neuromuscular block.

Acknowledgements Clinical investigators: Ana Aroca, Ana Gomez, Esther García-Villabona, Carmen Vallejo, Jesus Nieves, Ana Carmona, Diana Parrado, Rafael Morales.

Patient recruitment: Elena Rojo, Jara Torrente, Julia Hernando, Sonia Expósito, Elena Hernando, Marta Solera, David Arribas, Barbara Algar, Marina Valenzuela.

Provided care for study patients: General surgery department and operation room staff. Post-surgical critical care unit. University Hospital La Princesa, Madrid.

\section{Conflicts of interest None declared.}

Editorial responsibility This submission was handled by Dr. Gregory L. Bryson, Deputy Editor-in-Chief, Canadian Journal of Anesthesia.

Author contributions Enrique Alday was involved in the promotion, study design, patient recruitment, spirometry and lung ultrasound, data collection, data analysis, and writing of the manuscript. Manolo Muñoz was involved in the study design, spirometry and lung ultrasound, data collection, offline lung ultrasound analysis, planimetry, and writing of the manuscript. Carlos Alvarez was involved in the study design, patient recruitment, data collection, and revising the manuscript. Esperanza Mata was involved in the study design, patient recruitment, data collection, and revising the manuscript. Antonio Planas was involved in the study design and writing of the manuscript.

Funding This work was supported by a project grant from Merck Investigator Studies Program (MISP) (VT ID\# 51875) of 70,490 euros.

The study was sponsored but not monitored by the company. Merck had no role in or authority over the study design; collection, management, analysis, and interpretation of data; writing of the report; or the decision to submit the report for publication. The opinions expressed in this publication are those of the authors and do not necessarily represent those of the financer.

\section{References}

1. Ball L, Battaglini D, Pelosi P. Postoperative respiratory disorders. Curr Opin Crit Care 2016; 22: 379-85.

2. Fuchs-Buder T, Nemes R, Schmartz D. Residual neuromuscular blockade: management and impact on postoperative pulmonary outcome. Curr Opin Anaesthesiol 2016; 29: 662-7.

3. Martinez-Ubieto J, Ortega-Lucea S, Pascual-Bellosta A, et al. Prospective study of residual neuromuscular block and postoperative respiratory complications in patients reversed with neostigmine versus sugammadex. Minerva Anestesiol 2016; 82: 735-42.

4. Kumar GV, Nair AP, Murthy HS, Jalaja KR, Ramachandra K, Parameshwara G. Residual neuromuscular blockade affects postoperative pulmonary function. Anesthesiology 2012; 117 : 1234-44.

5. Brueckmann B, Sasaki N, Grobara $P$, et al. Effects of sugammadex on incidence of postoperative residual neuromuscular blockade: a randomized, controlled study. $\mathrm{Br} \mathrm{J}$ Anaesth 2015; 115: 743-51.

6. Cатmи G, Schepens T, De Neve N, Wildemeersch D, Foubert L, Jorens $P G$. Diaphragmatic and intercostal electromyographic activity during neostigmine, sugammadex and neostigminesugammadex-enhanced recovery after neuromuscular blockade: a randomised controlled volunteer study. Eur J Anaesthesiol 2016; 33: 8-15.

7. Anonymous. Standardization of spirometry, 1994 update. American Thoracic Society. Am J Respir Crit Care Med 1995; 152: 1107-36.

8. Lichtenstein DA. Lung ultrasound in the critically ill. Ann Intensive Care 2014; 4: 1.

9. Rueden $C T$, Eliceiri $K W$. Visualization approaches for multidimensional biological image data. Biotechniques 2007; 43(1 Suppl): 31, 33-6.

10. Rennard $S$, Fogarty $C$, Reisner $C$, et al. Randomized study of the safety, pharmacokinetics, and bronchodilatory efficacy of a proprietary glycopyrronium metered-dose inhaler in study patients with chronic obstructive pulmonary disease. BMC Pulm Med 2014; 14: 118.

11. Beeh KM, Moroni-Zentgraf $P$, Ablinger $O$, et al. Tiotropium Respimat ${ }^{\circledR}$ in asthma: a double-blind, randomised, dose-ranging study in adult patients with moderate asthma. Respir Res 2014; 15: 61 .

12. Treschan TA, Kaisers W, Schaefer MS, et al. Ventilation with low tidal volumes during upper abdominal surgery does not improve postoperative lung function. Br J Anaesth 2012; 109: 263-71.

13. Joris J, Kaba A, Lamy $M$. Postoperative spirometry after laparoscopy for lower abdominal or upper abdominal surgical procedures. Br J Anaesth 1997; 79: 422-6.

14. Treschan TA, Schaefer M, Kemper J, et al. Ventilation with high versus low peep levels during general anaesthesia for open abdominal surgery does not affect postoperative spirometry: a randomised clinical trial. Eur J Anaesthesiol 2017; 34: 534-43.

15. Kimball WR, Carwood CM, Chang Y, McKenna JM, Peters LE, Ballantyne JC. Effect of effort pain after upper abdominal surgery on two independent measures of respiratory function. $\mathrm{J}$ Clin Anesth 2008; 20: 200-5.

16. Duggan $M$, Kavanagh BP. Atelectasis in the perioperative patient. Curr Opin Anaesthesiol 2007; 20: 37-42.

17. Severgnini $P$, Selmo $G$, Lanza $C$, et al. Protective mechanical ventilation during general anesthesia for open abdominal surgery improves postoperative pulmonary function. Anesthesiology 2013; 118: 1307-21.

18. Yang D, Grant MC, Stone A, Wu CL, Wick EC. A meta-analysis of intraoperative ventilation strategies to prevent pulmonary 
complications: is low tidal volume alone sufficient to protect healthy lungs? Ann Surg 2016; 263: 881-7.

19. Guay J, Ochroch EA. Intraoperative use of low volume ventilation to decrease postoperative mortality, mechanical ventilation, lengths of stay and lung injury in patients without acute lung injury. Cochrane Database Syst Rev 2015; 12: CD011151.

20. Acosta CM, Maidana GA, Jacovitti D, et al. Accuracy of transthoracic lung ultrasound for diagnosing anesthesia-induced atelectasis in children. Anesthesiology 2014; 120: 1370-9.

21. Greco M, Capretti G, Beretta L, Gemma M, Pecorelli N, Braga $M$. Enhanced recovery program in colorectal surgery: a metaanalysis of randomized controlled trials. World J Surg 2014; 6: 1531-41.

22. Murphy GS, Szokol JW, Marymont JH, Greenberg SB, Avram MJ, Vender JS. Residual neuromuscular blockade and critical respiratory events in the postanesthesia care unit. Anesth Analg 2008; 107: 130-7.

23. Abrishami A, Ho J, Wong J, Yin L, Chung F. Sugammadex, a selective reversal medication for preventing postoperative residual neuromuscular blockade. Cochrane Database Syst Rev 2009; 4: CD007362.

24. Kirmeier E, Eriksson LI, Lewald $H$, et al. Post-anaesthesia pulmonary complications after use of muscle relaxants (POPULAR): a multicentre, prospective observational study. Lancet Respir Med 2019; 7: 129-40.

25. PROVE Network Investigators, for the Clinical Network of the European Society of Anaesthesiology; Hemmes SN, Gama de Abreu M, Pelosi P, Schultz MJ. High versus low positive endexpiratory pressure during general anaesthesia for open abdominal surgery (PROVHILO trial): a multicentre randomised controlled trial. Lancet 2014; 384: 495-503.

26. Ferrando $C$, Soro $M$, Unzueta $C$, et al. Individualised perioperative open-lung approach versus standard protective ventilation in abdominal Surgery (iPROVE): a randomised controlled trial. Lancet Respir Med 2018; 6: 193-203.

Publisher's Note Springer Nature remains neutral with regard to jurisdictional claims in published maps and institutional affiliations. 